\title{
DETECÇÃO DE SEQUÊNCIAS PROTEICAS IMUNOGÊNICAS DA NEURAMINIDASE DE Porphyromonas gingivalis ATCC 33277: AVALIAÇÃO IN SILICO COM ALELOS HLA-DR
}

\author{
Yuri Andrade de Oliveira ${ }^{1}$; Isaac Suzart Gomes Filho² ${ }^{2}$ Márcia Tosta Xavier $^{3}$; Ellen \\ Karla Nobre dos Santos Lima ${ }^{4}$; Ana Carla Montino Pimentel ${ }^{5}$; Thaise Passos Rocha ${ }^{6}$, \\ Soraya Castro Trindrade ${ }^{7}$ \\ 1. Bolsista PIBIC/FAPESB, Graduando em odontologia, Universidade Estadual de Feira de Santana, e-mail: \\ yuriandrade.odont@gmail.com \\ 2. Orientador, Departamento de Saúde, Universidade Estadual de Feira de Santana, e-mail: isuzart@gmail.com \\ 3. Participante do projeto, Escola Bahiana de Medicina e Saúde Pública, e-mail: tostamarcia@ gmail.com \\ 4. Participante do projeto, Programa de Pós-Graduação em Imunologia, Universidade Federal da Bahia, e-mail: \\ ellenobre@hotmail.com \\ 5. Participante do projeto, Programa de Pós-Graduação em Imunologia, Universidade Federal da Bahia, e-mail: \\ anacpimentel ba@hotmail.com \\ 6. Participante do projeto, Graduanda em odontologia, Universidade Estadual de Feira de Santana, e-mail: \\ thaisepassos@gmail.com \\ 7. Co-orientadora, Departamento de Saúde, Universidade Estadual de Feira de Santana, e-mail: \\ soraya.castrotrindade@gmail.com
}

PALAVRAS-CHAVE: periodontite; neuraminidase; Porphyromonas gingivalis.

\section{INTRODUÇÃO}

A periodontite é uma doença inflamatória que acomete os tecidos de suporte do dente, podendo levar à reabsorção do osso alveolar, destruição de fibras colágenas e, por fim, perda dentária (Lindhe, 1999). Esta enfermidade apresenta etiologia multifatorial, tendo como um dos principais agentes etiológicos a presença de um biofilme disbióticona região subgengival (Hajishengalis, 2014)).

Dentre os microrganismos presentes no biofilme, destaca-se Porphyromonas gingivalis, que é um bacilo gram-negativo, anaeróbio estrito, imóvel, intensamente proteolítico e um importante indutor de inflamação (Mayer et al., 2013). É um patógenochave na disbiose oral e é o microrganismo mais estudado em sua relação com a periodontite crônica (Hajishengallis \& Lambris, 2012).

$P$. gingivalis possui uma ampla gama de fatores de virulência, como hemaglutininas (Gao et al., 2010), LPS, fímbrias, polissacarídeo de superfície resistente ao complemento e proteases que degradam moléculas sinalizantes e citocinas (Preshaw \& Taylor, 2011).

As neuraminidases são proteínas sintetizadas por microrganismos patogênicos, incluindo $P$. gingivalis, e são consideradas fatores de virulência, contribuindo para a sua capacidade de induzir a doença periodontal (Teughels et al., 2011; Li et al., 2012).

Por outro lado, o reconhecimento desses fatores de virulência pelo sistema imune do hospedeiro ocorre por um sistema complexo de reconhecimento e sinalização da imunidade inata, culminando na apresentação de antígenos para os linfócitos $\mathrm{T}$ e ativação da imunidade inata. A maioria dos linfócitos $\mathrm{T}$ reconhece apenas peptídeos lineares curtos, pois seus receptores de antígenos (TCR) são específicos para antígenos apresentados por moléculas do MHC presentes na superfície das células apresentadoras de antígeno (APC) e tais moléculas se ligam a peptídeos. Os linfócitos $\mathrm{T} \mathrm{CD}^{+}{ }^{+}$reconhecem peptídeos provenientes de proteínas extracelulares, apresentados pelas moléculas MHC de classe II (Abbas et al., 2011).

Nos seres humanos, os genes que codificam o MHC localizam-se no braço curto do cromossoma 6. O HLA (MHC humano) de classe II possui três loci de genes, denominados HLA-DP, HLA-DQ e HLA-DR. Cada lócus contém vários genes separados denominados A ou $\mathrm{B}$, que codificam as cadeias $\alpha$ ou $\beta$, respectivamente. A nomenclatura do alelo HLA 
considera o enorme polimorfismo (variação entre indivíduos) identificado por métodos sorológicos e moleculares (Abbas et al., 2011).

Diante do exposto, o presente trabalho buscou identificar os epítopos peptídicos imunogênicos com afinidade para HLA, em seguida sintetizar as sequências peptídicas para depois utilizar em experimentos com cultivo celular para a compreensão do papel da neuraminidase na patogênese da periodontite crônica, bem como para posterior utilização em ensaios imunoenzimáticos que auxiliem no diagnóstico da doença.

\section{MATERIAL E MÉTODOS}

A identificação de peptídeos com potencial imunogênico foi realizada por bioinformática, utilizando programas disponíveis online (Yang \& Yu, 2009), a exemplo do estudo realizado por Bittner-Eddy et al. (2013). A sequência da proteína Neuraminidase de $P$. gingivalis ATCC 33277 foi adquirida no banco de dados do NCBI (National Center for Biotechnology Information) - BAG34127.1 - e foi analisada para a predição de peptídeos que se liguem a receptores MHCII humanos (HLA-DR) e induzam uma resposta imune celular e humoral. Para a predição, foi utilizada a ferramenta MHC-II Binding Predictions (http://tools.immuneepitope.org/mhcii/) do IEDB (Immune Epitope Database) (Yang \& Yu, 2009; Vita et al., 2010). Após a predição, os peptídeos com alta afinidade (menor rank percentual) foram selecionados para síntese química e avaliação in vitro da capacidade de induzir resposta em células T CD4 ${ }^{+}$.

\section{RESULTADOS E DISCUSSÃO}

A predição resultou em 12 sequências peptídicas com 15 resíduos de aminoácidos (15mer) (Quadro 1). Dentre os peptídeos imunogênicos putativos obtidos, 7 estão no domínio BNR (Bacterial Neuraminidase Repeat). Desses, 02 peptídeos incluem sítios catalíticos da enzima. Não houve formação de grupos de sequências por similaridade (Identity Threshold 90\%), confirmando serem sequências diferentes entre si. Não houve similaridade com as sequências depositadas no IEDB (Exact Matches / 100\%), indicando o ineditismo das sequências obtidas. 


\begin{tabular}{|c|c|c|c|c|c|c|c|c|}
\hline \multirow[b]{2}{*}{ Proteína } & \multirow[b]{2}{*}{ Alelo HLA } & \multirow[b]{2}{*}{ Código } & \multirow[b]{2}{*}{ Peptídeo } & \multirow[b]{2}{*}{ Início } & \multirow[b]{2}{*}{ Fim } & \multicolumn{3}{|c|}{ Protein Database (NCBI)* } \\
\hline & & & & & & $\begin{array}{l}\text { Sialidase } \\
(\mathbf{1 8 2 - 5 1 7})\end{array}$ & $\begin{array}{c}\text { Domínio } \\
\text { BNR*** } \\
(204-500)\end{array}$ & $\begin{array}{c}\text { Sítio } \\
\text { catalítico } \\
\text { / ativo } \\
\text { (Resíduo) } \\
\#\end{array}$ \\
\hline \multirow{12}{*}{$\begin{array}{c}\text { Neuraminidase } \\
\quad(526 \mathrm{aa})\end{array}$} & DRB3*01:01 & N7 & $\begin{array}{c}\text { YSDMTL } \\
\text { LADGTI } \\
\text { GYF }\end{array}$ & 488 & 502 & $\mathrm{X}$ & $\mathrm{X}$ & 488 \\
\hline & DRB3*01:01 & N8 & $\begin{array}{c}\text { PDYKGR } \\
\text { VSYDSFP } \\
\text { IS }\end{array}$ & 98 & 112 & & & \\
\hline & DRB4*01:01 & N9 & $\begin{array}{l}\text { ALYLLV } \\
\text { SDSLAV } \\
\text { RDL }\end{array}$ & 83 & 97 & & & \\
\hline & DRB4*01:01 & N10 & $\begin{array}{l}\text { LMAMM } \\
\text { HLSGQE } \\
\text { VTMW }\end{array}$ & 22 & 36 & & & \\
\hline & DRB5*01:01 & N11 & $\begin{array}{c}\text { KQIRIGF } \\
\text { SLPKETE } \\
\text { E }\end{array}$ & 65 & 79 & & & \\
\hline & DRB5*01:01 & N12 & $\begin{array}{l}\text { KTANGT } \\
\text { LIAMAD } \\
\text { RRK }\end{array}$ & 200 & 214 & $\mathrm{X}$ & $\mathrm{X}$ & \\
\hline & DRB1*13:02 & N13 & $\begin{array}{c}\text { IPSILKT } \\
\text { ANGTLI } \\
\text { AM }\end{array}$ & 195 & 209 & $\mathrm{X}$ & $\mathrm{X}$ & \\
\hline & DRB1*13:02 & N14 & $\begin{array}{c}\text { VALVQT } \\
\text { QAGKLL } \\
\text { MIF }\end{array}$ & 257 & 271 & $\mathrm{X}$ & $\mathrm{X}$ & \\
\hline & DRB1*15:01 & N15 & $\begin{array}{c}\text { QAGKLL } \\
\text { MIFVGG } \\
\text { VGL }\end{array}$ & 263 & 277 & $\mathrm{X}$ & $X$ & \\
\hline & DRB1*15:01 & N16 & $\begin{array}{c}\text { PASRRL } \\
\text { YREYEA } \\
\text { LFV }\end{array}$ & 170 & 184 & $\mathrm{X}$ & & \\
\hline & DRB $1 * 07: 01$ & N17 & $\begin{array}{c}\text { FGDVAL } \\
\text { VQTQAG } \\
\text { KLL }\end{array}$ & 254 & 268 & $\mathrm{X}$ & $\mathrm{X}$ & \\
\hline & DRB1*07:01 & N18 & $\begin{array}{c}\text { YRIPSIL } \\
\text { KTANGT } \\
\text { LI }\end{array}$ & 193 & 207 & $\mathrm{X}$ & $\mathrm{X}$ & 194 \\
\hline
\end{tabular}

Quadro 1. Sequências peptídicas de Neuraminidase. Início e fim correspondem à posição na sequência proteica.

*Acesso Protein Database BAG34127.1

**Domínio BNR (Bacterial Neuraminidase Repeat)

\#Resíduos 194, 219, 382, 398, 460, 488 e 504.

\section{CONSIDERAÇÕES FINAIS}

A análise in silico possibilitou a seleção dos peptídeos preditos antes de serem sintetizados. Após a síntese química, os peptídeos imunogênicos integrarão estudos da reposta imune do hospedeiro diante do desafio por $P$. gingivalis na periodontite crônica.

\section{REFERÊNCIAS}

ABBAS AK, LICHTMAN AH, PILLAI S. Moléculas do complexo principal dehistocompatibilidade e apresentação do antígeno aos linfócitos T. In: ImunologiaCelular e Molecular. 7ed. Rio de Janeiro: Elsevier, 2011. p. 109-38.

BITTNER-EDDY, P.D.; FISCHER, L.A.; COSTALONGA, M. Identification of gingipainspecific I-Ab-restricted CD4+ T cells following mucosal colonization with Porphyromonas gingivalis in C57BL/6 mice. Molecular oral microbiology, v. 28, p. 452-66, 2013.

GAO, J.; NGUYEN, K.; HUNTER, N. Characterization of a hemophore-like protein from Porphyromonas gingivalis. The Journal of Biological Chemistry, v. 285, n. 51, p. 4002840038, 2010. 
HAJISHENGALLIS, G.; LAMBRIS, J.D. Complement and dysbiosis in periodontal disease. J. Immunobiology, v. 217, p. 1111-1116, 2012.

HAJISHENGALLIS G. Immunomicrobial pathogenesis of periodontitis: keystones, pathobionts, and host response. Trends Immunol. 2014; 35(1):3-11.

LINDHE J. Tratado de periodontia clínica e implantologia oral. 3ed. Rio de Janeiro: Guanabara Koogan,1999.

MAYER, M.P.A.; SUGUIMOTO, E.S.A.; TEIXEIRA, S.R.L. Microbiologia da doença periodontal. In: SPOLIDORIO, D.M.P.; DUQUE, C. Microbiologia e imunologia geral e odontológica. v.1. São Paulo: Artes Médicas, 2013. p. 91-99.

PRESHAW, P.M.; TAYLOR, J.J. Patogênese periodontal. In: NEWMAN, M.G.; TAKEI, H.; KLOKKEVOLD, P.R.; CARRANZA, F.A. Carranza, periodontia clínica. 11ed. Rio de Janeiro: Elsevier, 2011. p. 210-35.

TEUGHELS, W.; QUIRYNEN, M.; JAKUBOVICS, N. Microbiologia periodontal. In: NEWMAN, M.G.; TAKEI, H; KLOKKEVOLD, P.R.; CARRANZA, F.A. Carranza, periodontia clínica. 11ed. Rio de Janeiro: Elsevier, 2011. p. 251-94.

VITA R, ZAREBSKI L, GREENBAUM JA, EMAMI H, HOOF I, SALIMI N, DAMLE R, SETTE A, PETERS B. The immuneepitopedatabase 2.0. NucleicAcids Res. 2010;38(Databaseissue):D854-62.

YANG, X.; YU, X. An introduction to epitope prediction methods and software. Rev. Med. Virol., v. 19, n. 2, p. 77-96, 2009. 